\title{
Density estimates of monarch butterflies overwintering in central Mexico
}

\author{
Wayne Thogmartin ${ }^{\text {Corresp., }}{ }^{1}$, Jay E Diffendorfer ${ }^{2}$, Laura Lopez-Hoffman ${ }^{3}$ ， Karen Oberhauser ${ }^{4}$, John Pleasants ${ }^{5}$ \\ , Brice Xavier Semmens ${ }^{6}$, Darius Semmens ${ }^{2}$, Orley R Taylor ${ }^{7}$, Ruscena Wiederholt ${ }^{8}$ \\ 1 Upper Midwest Environmental Sciences Center, United States Geological Survey, La Crosse, Wisconsin, United States \\ 2 Geosciences and Environmental Change Science Center, United States Geological Survey, Lakewood, Colorado, United States \\ 3 School of Natural Resources and the Environment and Udall Center for Studies in Public Policy, University of Arizona, Tucson, Arizona, United States \\ 4 Department of Fisheries, Wildlife and Conservation Biology, University of Minnesota, St. Paul, Minnesota, United States \\ 5 Department of Ecology, Evolution, and Organismal Biology, lowa State University, Ames, lowa, United States \\ 6 Scripps Institution of Oceanography, University of California, San Diego, La Jolla, California, United States \\ 7 Department of Ecology and Evolutionary Biology, University of Kansas, Lawrence, Kansas, United States \\ 8 Everglades Foundation, Palmetto Bay, FL, United States \\ Corresponding Author: Wayne Thogmartin \\ Email address: wthogmartin@usgs.gov
}

Given the rapid population decline and recent petition for listing of the monarch butterfly (Danaus plexippus L.) under the Endangered Species Act, an accurate estimate of the Eastern, migratory population size is needed. Because of difficulty in counting individual monarchs, the number of hectares occupied by monarchs in the overwintering area is commonly used as a proxy for population size, which is then multiplied by the density of individuals per hectare to estimate population size. There is, however, considerable variation in published estimates of overwintering density, ranging from 6.9-60.9 million ha $^{-1}$. We develop a probability distribution for overwinter density of monarch butterflies from six published density estimates. The mean density among the mixture of the six published estimates was $\sim 27.9$ million butterflies ha-1 (95\% Cl: 2.4-80.7 million ha-1); the mixture distribution is approximately log-normal, and as such is better represented by the median (21.1 million butterflies ha-1). Based upon assumptions regarding the number of milkweed needed to support monarchs, the amount of milkweed (Asclepias spp.) lost ( 0.86 billion stems) in the northern U.S. plus the amount of milkweed remaining (1.34 billion stems), we estimate $>1.8$ billion stems is needed to return monarchs to an average population size of 6 ha. Considerable uncertainty exists in this required amount of milkweed because of the considerable uncertainty occurring in overwinter density estimates. Nevertheless, the estimate is on the same order as other published estimates. The studies included in our synthesis differ substantially by year, location, method, and measures of precision. A better understanding of the factors influencing overwintering density across space and time would be valuable for increasing the precision of 


\section{conservation recommendations.}


1 Density estimates of monarch butterflies overwintering in central Mexico

2

3 Running Title: Overwinter density of monarch butterflies

4

5 Wayne E. Thogmartin1@, Jay E. Diffendorfer², Laura López-Hoffman ${ }^{3}$, Karen Oberhauser ${ }^{4}$, John

6 Pleasants $^{5}$, Brice Semmens ${ }^{6}$, Darius Semmens ${ }^{2}$, Orley R. Taylor ${ }^{7}$, and Ruscena Wiederholt ${ }^{8}$

$8{ }^{1}$ United States Geological Survey, Upper Midwest Environmental Sciences Center, La Crosse,

9 WI, USA, wthogmartin@usgs.gov

10 'United States Geological Survey, Geosciences and Environmental Change Science Center,

11 Lakewood, CO, USA, jediffendorfer@usgs.gov, dsemmens@usgs.gov

${ }^{3}$ School of Natural Resources and the Environment and Udall Center for Studies in Public

Policy, The University of Arizona, Tucson, AZ, USA, lauralh@email.arizona.edu,

rpw143@gmail.com

${ }^{4}$ Department of Fisheries, Wildlife and Conservation Biology, University of Minnesota, St Paul, MN, USA, oberh001@umn.edu

${ }^{5}$ Department of Ecology, Evolution, and Organismal Biology, Iowa State University, Ames, IA, USA, jpleasan@iastate.edu

${ }^{6}$ Scripps Institution of Oceanography, University of California, San Diego, 9500 Gilman Drive,

La Jolla CA, USA, semmens@ucsd.edu

${ }^{7}$ Department of Ecology and Evolutionary Biology, University of Kansas, Lawrence, KS, USA, 22 chip@ku.edu

${ }^{8}$ Everglades Foundation, Palmetto Bay, FL 33157

@Order of authorship is alphabetical after the first author.

*Correspondence to: Wayne E. Thogmartin, United States Geological Survey, Upper Midwest 
Abstract

32 Given the rapid population decline and recent petition for listing of the monarch butterfly

33

34

(Danaus plexippus L.) under the Endangered Species Act, an accurate estimate of the Eastern, migratory population size is needed. Because of difficulty in counting individual monarchs, the number of hectares occupied by monarchs in the overwintering area is commonly used as a proxy for population size, which is then multiplied by the density of individuals per hectare to estimate population size. There is, however, considerable variation in published estimates of overwintering density, ranging from 6.9-60.9 million ha-1. We develop a probability distribution for overwinter density of monarch butterflies from six published density estimates. The mean density among the mixture of the six published estimates was $\sim 27.9$ million butterflies ha ${ }^{-1}(95 \%$ CI: $2.4-80.7$ million $^{-1}$ ); the mixture distribution is approximately log-normal, and as such is better represented by the median (21.1 million butterflies ha-1). Based upon assumptions regarding the number of milkweed needed to support monarchs, the amount of milkweed (Asclepias spp.) lost (0.86 billion stems) in the northern U.S. plus the amount of milkweed remaining ( 1.34 billion stems), we estimate $>1.8$ billion stems are needed to return monarchs to an average population size of 6 ha. Considerable uncertainty exists in this required amount of milkweed because of the considerable uncertainty occurring in overwinter density estimates. Nevertheless, this milkweed estimate is on the same order as other published estimates. The studies included in our synthesis differ substantially by year, location, method, and measures of precision. A better understanding of the factors influencing overwintering density across space and time would be valuable for increasing the precision of conservation recommendations. 
53

54

55

56

57

58

59

60

61

62

63

64

65

66

67

68

69

70

71

72

73

74

Introduction

"I can see no other escape from this dilemma (lest our true aim be lost forever) than that some of us should venture to embark on a synthesis of facts and theories, albeit with second hand and incomplete knowledge of some of them - and at the risk of making fools of ourselves.” (Erwin Schrödinger, 1944:1)

Monarch butterflies overwintering in the high-elevation Oyamel fir (Abies religiosa) forests of central Mexico form spectacular aggregations thought to number in the millions of individuals per hectare (Urquhart \& Urquhart, 1976; Brower, 1977). The cool temperatures of these highelevation sites allow monarchs to slow their metabolism, conserving lipid reserves for the approximately 5-month wintering period. Clustering in densely packed colonies on the lower branches of Oyamel fir trees also minimizes mortality during cold and rainy winter nights (Anderson \& Brower, 1996; Brower et al., 2009; Williams \& Brower, 2015) and increases humidity, thus reducing evaporation and desiccation as the dry season advances (Brower et al., 2008). In early spring, migration of monarchs over much of eastern North America resumes from this location, a multi-generational migratory phenomenon seen in few other insects.

Since winter 1994-1995, World Wildlife Fund-Mexico (WWF) in collaboration with the Mexican Secretariat of Environment and Natural Resources (Secretaría de Medio Ambiente y Recursos Naturales; SEMARNAT), the National Commission for Protected Areas (Comisión Nacional de Áreas Naturales Protegidas; CONANP), and the Monarch Butterfly Biosphere Reserve (MBBR) have monitored the overwintering population. The winter monitoring consists of estimating the area over which these densely packed colonies occur (Calvert and Brower, 
1986; Garcia-Serrano et al., 2004; Slayback et al., 2007; Vidal et al., 2014; Vidal \& RendónSalinas, 2014; Rendón-Salinas \& Tavera-Alonso, 2015). Occupied trees are mapped in each colony and the perimeter of the colony is measured. The enclosed area is then calculated in hectares occupied and used as an index of population size.

This monitoring of the Eastern population of monarch butterflies (Danaus plexippus) in North America suggests large declines in the wintering population size over the last decade and a half (Semmens et al., 2016). The largest population size recorded since monitoring began in the early 1990s was 18.19 ha in winter 1996-1997. Since this peak in abundance, monitoring suggests that the population has declined by over 90\% (Brower et al., 2012; Vidal \& RendónSalinas, 2014; Rendón-Salinas \& Tavera-Alonso, 2015), to a record low of 0.67 ha in winter 2013-2014 (Rendón-Salinas \& Tavera-Alonso, 2015). These declines in abundance are believed to be due, in large part, to declines in habitat availability in the breeding range of the northcentral United States, principally through loss of common milkweed (Asclepias syriaca) in agricultural crops (Pleasants \& Oberhauser, 2013; Pleasants, 2015, 2017), as well as forest degradation in the Mexican overwintering habitat (Brower et al. 2016).

In 2014, due to concerns over these overwintering population declines, the U.S. Fish and Wildlife Service was petitioned to list monarchs as a threatened species under the Endangered Species Act (Center for Biological Diversity et al., 2014; docket number FWS-R3-ES-20140056). The agency subsequently initiated a status review to determine whether listing for the entire species was warranted. The White House announced a strategic goal of increasing the eastern population of the monarch butterfly to 225 million butterflies by 2020 (Pollinator Health Task Force, 2015). This 225 million butterfly goal was motivated in part by the premise that 225 million butterflies equated to 6 ha of habitat occupied by monarch butterflies in overwintering 
98 sites (Pollinator Health Task Force, 2015), or 37.5 million butterflies ha-1 ${ }^{-1}$ The magnitude of this

99 target for the Eastern migratory population of monarch butterflies has important implications for

100 the estimated level of restoration effort (i.e., increasing milkweeds) needed to sustain the

101 population in eastern North America. Therefore, accurate determination of the overwintering

102 population size, not just the area over which it occurs in winter, is a critical step in determining

103 the magnitude of the conservation challenge.

To translate from colony extent to population numbers, estimates of the area occupied by overwintering aggregations must be multiplied by an estimate of density (monarchs/unit area).

Current understanding of the overwintering densities of monarch butterflies in these aggregations comes from a handful of published sources, principally Brower et al., (1977), Brower et al., (2004) and Calvert (2004). Brower et al., (1977) and Tuskes \& Brower, (1978) used density estimates from capture-mark-recapture for California overwintering colonies for a rough estimate of abundance in Mexico. They multiplied the density estimate for Santa Cruz, California, which was 95,000 butterflies ha-1 ${ }^{-1}$ by 15 to account for the difference in area covered by Mexican and

112 Californian colonies, and again by 10 to account for their suggestion that California colonies were $10 \%$ of the density of the Mexican colony. Their suggestion of 14.25 million monarch butterflies occupying 1.5 hectares in one location in Mexico was deemed "a conservative estimate" of 9.5 million monarch butterflies ha-1 ${ }^{-1}$ It was not until nearly a quarter-century later that attempts at calculating density using on-site measurements made in Mexico were published.

117 Calvert (2004) used two approaches with capture-mark-recapture data to estimate population densities of 21 to 100 million monarchs ha ${ }^{-1}$, with higher densities occurring later in the season when the colony had contracted. At a different colony, Calvert (2004) measured monarch density on a sub-sample of tree branches and trunks and generated an estimate of 10.3 million monarchs 
121 ha-1. Brower et al., (2004) took a different tack, extrapolating the density of monarchs killed

122 during a winter storm (in January 2002) at two sites, and obtained estimated densities of 53 and

12373 million monarchs ha ${ }^{-1}$ for the two sites, for a mean estimate of 65 million monarchs ha-1 ${ }^{-1}$ This

124 mean estimate was subsequently revised down to 50 million monarchs ha ${ }^{-1}$ (Slayback et al.,

125 2007) to be more conservative (L. Brower, personal communication). Obviously, considerable

126 variation exists in the estimates of overwintering densities, which has important policy

127 ramifications for their use by groups working together to chart a strategy for protecting

128 monarchs, including the US Fish and Wildlife Service, other partner agencies in the US, Mexico

129 and Canada, and non-governmental actors.

Accurate estimation of the density of monarch butterfly populations overwintering in

131 Mexico provides critical information for determining the abundance of the Eastern migratory

132 population. Uncertainties in these density estimates may arise from many different sources such

133 as natural variability in the monarch's response to environmental conditions, including their own

134 population numbers, and variability in environmental stressors over time and space (Williams

135 and Brower, 2016). Incomplete knowledge regarding a situation or variable, often occurring as a

136 result of measurement (or observation) error, unstated assumptions or extrapolations, also

137 contributes uncertainty in density estimates. Methods have been developed for estimating

138 variables when faced with stochastic variation and incomplete knowledge (McLachlan \& Peel,

139 2000; Zadeh, 2002; Pearson, 2011). Based on the form of available information, probability

140 theory can be used to incorporate parameter uncertainty and variability into an expected value

141 distribution (Shapiro, 2009). The expected value distribution describes the distribution around

142 the expected value, or the weighted average of all possible outcomes. Here we used finite

143 mixture distribution modeling to derive the expected distribution of monarch overwintering 
144 density from the estimates of Calvert (2004) and Brower et al., (2004). We then applied the

145 median estimated abundance from that distribution to a corrected time series of overwinter

146 abundance (Semmens et al., 2016) to understand the magnitude of population change since

147 systematic monitoring for wintering monarchs began in the early 1990s. We also propose an

148 environmental correlate to changing within-season density. Additionally, we used our estimated

149 density to estimate the amount of milkweed needed to sustain the 6-ha goal population.

151 Methods

152

We calculated the fuzzy random variable for monarch density using two general steps.

153 First, for each of six available estimates of density, we calculated the uncertainty around the

154 estimated central tendency (estimated mean or reported value) and then modeled this using a

155 lognormal distribution (except in one case, where extreme values required an extreme value

156 distribution). Patterns in species abundance are often lognormal (Sugihara, 1980, Limpert et al.,

157 2001). This resulted in five lognormal distributions and one extreme value distribution, each

158 centered on the original point estimate of density (Table 1). We then combined the six

159 distributions to estimate a new, combined distribution of density incorporating putative levels of

160 uncertainty in the underlying reported estimates. The six available estimates of density come

161 from two sources, four estimates from Calvert (2004) and two from Brower et al., (2004).

calculating mean and 95\% confidence interval estimates of overwinter density from the capture

164 records of tagged butterflies in late December 1985 and mid-January 1986. The reported confidence intervals were asymmetrical. We approximated the population standard deviations, 
166 on the natural log scale, from these confidence intervals according to $\tilde{\sigma}=($

$\left.167 \frac{\log (\text { mean })-\log (\text { lower } 95 \% \text { limit })}{2.11}+\frac{\log (\text { upper } 95 \% \text { limit })-\log (\text { mean })}{2.11}\right) / 2$, where 2.11 is the $t$ critical value

168 under the assumption of a small sample size. Using the reported mean and estimated standard

169 deviations, we fit both gamma and lognormal distributions (Wilks, 2006); the lognormal

170 distribution fit the published confidence intervals best (matched most closely) and was used in

171 the analysis.

Calvert (2004) also estimated overwinter density from a sample of monarch butterflies

173 collected from branches and tree trunks in 1977 . He used 12 branches of varying size to regress

174 monarch abundance against branch size, and then used data on tree structure to estimate the

175 average size and number of branches for trees of different sizes. He then measured the number of

176 monarchs on 17 different tree trunks. He summed "crown monarchs" (on branches) and "trunk

177 monarchs" to obtain an estimate of monarchs per tree. This branch-based estimate of density was

178 reported without a measure of associated variance. Therefore, we treated Calvert's branch-based

179 estimate as a Fermi approximation (Machtans and Thogmartin 2014), a rough estimate for a

180 difficult-to-estimate quantity, and inferred the variance to be a function of the number of

181 parameters in the branch and trunk calculations. We assumed this estimate was correct within a

182 factor of two; this range gives this estimate similar precision as the other January estimates of

183 density. Thus, given this assumption, we calculated the upper limit in the crown and trunk

184 estimates as $2^{\sqrt{n}} \times$ mean of the crown and trunk estimate, respectively, where $n$ equaled the

185 number of parameters used in the calculation of the estimate. The lower limit was similarly

186 calculated but with the inverse of $2^{\sqrt{n}}$ as the multiplier. Based on our reading of Calvert (2004),

187 we surmised there were 5 parameters in the crown estimate (diameter at breast height, crown

188 mass, branches per crown, tree density, monarch weight) and 3 in the trunk estimate (surface 
189 area of a column, monarch sample density, tree density). Once the lower and upper limits in the 190 estimates were established, the standard deviation was estimated as above for Calvert capture191 mark-recapture data. Conejos) in mid-January 2002, and thereafter assumed a midpoint as the nominal mean density of colonies. We were provided the original data used in extrapolating storm mortality observations to hectare-scale density estimates. Details of data collection are provided by Brower et al., (2004) but, briefly, the data comprise of counts made of dead and moribund individuals observed in $290.2 \mathrm{~m} \times 0.2 \mathrm{~m}$ plots in each of the two colonies. The mortality data are highly skewed, particularly those data from the Conejos colony (Appendix A); for example, $>1,000$ dead and moribund monarch butterflies were counted in a single $0.04 \mathrm{~m}^{2}$ plot. For the Zapatero colony, we fit a lognormal distribution to the observed counts, whereas for the highly skewed Conejos colony we fit a generalized extreme value distribution. The generalized extreme value distribution is characterized by mean $\mathrm{E}[\mathrm{X}]=\zeta-\beta[1-\Gamma(1-\kappa)] / \kappa$ and variance $\operatorname{Var}[\mathrm{X}]=\beta^{2}(\Gamma$

$\left.203[1-2 \kappa]-\Gamma^{2}[1-\kappa]\right) / \kappa^{2}$ (Wilks 2006:87), where $\kappa$ is a shape parameter, $\zeta$ is a location or shift parameter, and $\beta$ is a scale parameter. Because these distributions provide the expected count for a $0.04 \mathrm{~m}^{2}$ area, we then extrapolated this distribution to the hectare scale (by multiplying by $250,000)$ to make them commensurate in scale with the other published estimates of density. based on measurements from three years $(1979,1985-1986,2002)$. These estimates (aside from one) are presumptively drawn from lognormal distributions. Elementary probability theory cannot describe the distribution of the sum of lognormals (Dufresne, 2004). Thus, we relied on 
212 developed a mixed probability density function $g$ as an equal-weighted sum of $k$ component

213 densities:

$214 g(\chi \mid x, \mu, \sigma)=\pi_{1} f\left(\chi \mid \mu_{1}, \sigma_{1}\right)+\ldots \pi_{k} f\left(\chi \mid \mu_{k}, \sigma_{k}\right)$, where $k$ is equal to the six distributions

215 described above. We created this distribution by drawing $10^{6}$ samples randomly from each

216 distribution and then combining the drawn samples. Measures of central tendency and $2.5 \%$ and

$21797.5 \%$ quantile estimates were derived from the resulting mixture distribution. roost suitability (Anderson \& Brower, 1996; Brower et al., 2008, 2009, 2011). For instance, freezing dew on the surface of exposed butterflies can lower their supercooling resistance, ostensibly because ice crystals invade the spiracles of the butterflies, providing nucleation centers in the supercooled body fluids, which then may freeze (Anderson and Brower 1996). endpoint), we quantified the observation that monarch butterflies pack more tightly with decreasing winter temperature (Brower et al., 2011; Vidal \& Rendón-Salinas, 2014) by regressing the observed pattern of density to daily mean temperature and daily mean dew point

227 (for the closest location for which these data were available, Toluca, Mexico, for the period 1977-2014; US National Climatic Data Center (NCDC) Global Summary of the Day, http://www7.ncdc.noaa.gov/CDO/cdodata.cmd, Downloaded Tue Dec 22 09:42:55 EST 2015). which water condenses; dew point is often correlated with minimum temperature, especially when humidity is high. 
235 (2015) used Monarch Larva Monitoring Program egg density and survival data to estimate the 236 number of milkweed plants needed to produce an adult monarch migrating to Mexico. Their

237 calculations (see their equation 2) resulted in an estimate of 28.5 milkweed stems per monarch

238 necessary to produce one adult for the fall migration. With this estimate from Nail et al., (2015),

239 we translated the 6 ha overwintering goal for monarchs into numbers of milkweed stems, under 240 average climatic conditions (Pleasants, 2017).

We also applied the derived density estimate to the time series of overwintering

242 abundances to estimate potential change in monarch population size through time. Semmens et

243 al., (2016) used a state-space formula for estimating a corrected time series of the areal estimate

244 of the overwinter population size. This state-space formula enabled estimation of the underlying

245 true state of the population corrected for observation noise. We multiplied the corrected estimate

246 of areal overwinter population size by the median of the mixture distribution to calculate the

247 annual monarch butterfly population abundance (given constant annual density).

249 Results

Reconstructed distributions matched the means reported by Calvert (2004); the January

251

252

253

254

255

256 capture-mark-recapture distributions showed high levels of uncertainty and overlapped each other, but were significantly larger than the January branch-based method (Figure 1). The January branch-based method roughly coincided with the mean of the December capture-markrecapture distribution. The Brower et al., (2004) storm-mortality approach and the Calvert (2004) January capture-mark-recapture methods reported results two to four times higher than the Calvert (2004) branch and December Petersen capture-mark-recapture methods (Figure 1). 
pronounced spike due largely to the branch-based and December Petersen capture-mark-

million butterflies $\mathrm{ha}^{-1}$, respectively $(2.5 \%$ quantile $=2.4,97.5 \%$ quantile $=80.7$ million butterflies $\left.\mathrm{ha}^{-1}\right)$.

Density regressed against temperature, dew point, and day of year most strongly

263

264

265 supported a negative relationship between density and dew point (Table 2, Figure 3a). When dew point is nearest $0^{\circ} \mathrm{C}$, monarch density is predicted to be greatest. Temperature and dew point in central Mexico are both lowest in mid-January (Figure 3b).

assuming constant annual density during winter monitoring, the time series of overwinter population size suggested monarch butterflies may have numbered 310 million individuals in winter 1996-1997 and dropped to as low as 37 million in winter 2013-2014, nearly an order of magnitude difference (Table 3, Figure 4). The mean annual abundance over this 20-year period was 119 million butterflies (95\% CI: 69-212 million).

A 6-ha population goal using the median of the six-estimate mixture distribution equated to a mean of 127 million monarchs $\left(6 \mathrm{ha} \times 21.1\right.$ million ha $\left.^{-1}\right)$. Assuming 28.5 milkweed stems are needed to produce a single monarch (Nail et al., 2015), 127 million monarchs equaled $\sim 3.62$ billion stems (127 million monarchs $\times 28.5$ milkweed/monarch).

277 Discussion 

available published data, we suggest the preponderance of evidence supports a median overwintering density of monarchs of 21.1 million butterflies ha ${ }^{-1}(2.5 \%$ quantile $=2.4$ million butterflies ha-1, $97.5 \%$ quantile $=80.7$ million butterflies ha-1 ${ }^{-1}$. The few observations we have suggest monarch density changes with dew point, likely increasing in density from lateDecember to a peak in mid-January as the temperature cools. This change over time in density coincides with the observations of Vidal \& Rendón-Salinas (2014). Vidal \& Rendón-Salinas (2014) suggested clusters of overwintering monarchs disaggregate when temperature increases, which is coherent with the temperature-density relation we report. to considerably different conclusions than had we used the estimate they reported. If we had used their 50 million ha-1 estimate as one of five (not six) samples in our analyses, we would have estimated a mixture distribution with a mean and median of 45.7 million butterflies ha ${ }^{-1}$, respectively (code for analysis available in Code Supplement). This estimate is twice our estimated median (21.1 million ha ${ }^{-1}$ ). The reason Brower et al. (2004) concluded a density estimate of 50 million $\mathrm{ha}^{-1}$ rather than the 15.9 and 18.3 million $\mathrm{ha}^{-1}$ we report is because they used the mean to characterize the skewed distributions of their samples, a mean skewed to higher values by a few outlying estimates. Samples from both the Conejos and Zapatero colonies are small $(n=29)$ and skewed by a few very large counts (Appendix A). For sufficiently large samples, the distribution of the sample mean is approximately normal according to the Central Limit Theorem. At the sample sizes reported by Brower et al. (2004), we cannot be assured that the Central Limit Theorem holds. The preponderance of the observed data and the mass of the resulting distributions fitted to those data are considerably smaller than the mean (e.g., median 
301 for Conejos colony was 86 butterflies per sample versus a mean of 290 butterflies per sample).

302 As a result, the values we drew from the fitted distributions for Conejos and Zapatero colonies

303 led to a lower expected density than if we had used the higher published estimate.

304

305

306

307

308

309

310

311

312

313

314

315

316

317

318

319

320

321

322

The North American Climate, Clean Energy, and Environment Partnership Action Plan

(Trudeau et al., 2016) identified the restoration target of a 6-ha overwinter abundance of

monarch butterflies as a goal to be achieved by Canada, the U.S., and Mexico by 2020. This 6-ha

target is equivalent to approximately 127 million monarchs ${ }^{1}$ (with a putative $95 \%$ confidence

interval of 14-484 million) according to estimated median overwinter density. One of the central

outstanding questions for conserving monarchs is, how much milkweed must be planted to create sufficient habitat to support this target population size? Pleasants (2017) suggested the loss of milkweed in the North Central region of the U.S. between 1999 and 2014 amounted to 862 million stems, with an additional 1.34 billion stems remaining. Pleasants (2017) argued that milkweed in corn and soybean fields produced 3.9 times more monarch eggs than milkweeds in non-agricultural habitat (see Pleasants and Oberhauser 2013) and that, therefore, the loss of

Midwestern agricultural fields was especially hard hitting to monarchs; he suggested that the loss of 850 million stems in corn and soy fields amounted to the equivalent of 3.31 billion nonagricultural stems of milkweed. Similarly, we estimate a 127 million monarch population would require 3.62 billion stems of milkweed; with 1.34 billion stems remaining in the landscape, the milkweed deficit could be as high as 2.28 billion stems, or $\sim 700$ million more stems than was needed according to Pleasants (2017) to return the population to 6 ha of occupied overwintering habitat. Alternatively, if we subtract the estimated amount of milkweed needed for a 126 million monarch population (i.e., 6 ha) from the equivalent needed for what Pleasant (2017) estimated

${ }^{1}$ Similar to a return to the 1998-1999 overwinter population, which was 6.02 ha and 137 million monarchs [71-267 million] (Table 2). 
323 remains (3.15 ha, or $\sim 70$ million monarchs), we obtain 1.8 billion stems ( $95 \%$ CI: $0.7-4.70$

324 billion stems), or 200 million stems more than estimated by Pleasants (2017). These calculations

325 assume a linear relationship between monarch and milkweed abundance but Pleasants (2017)

326 demonstrated it was linear on the log-scale (i.e., Number of milkweed stems $=\mathrm{e}^{0.12 \times \mathrm{OW}[\mathrm{ha}]+7.24}$,

327 where OW[ha] is number of hectares of butterflies overwintering in Mexico), indicating that our

328 estimates of the milkweed deficit provide liberal upper bounds on what may be required.

Clearly, despite our best efforts at synthesizing the available information pertaining to overwinter density, there remains considerable uncertainty in the estimated densities, which in turn influences uncertainty in subsequent calculations of population size and associated levels of milkweed needed to sustain the species. Mixture distributions are often developed when data are believed to arise from more than one generation process or physical mechanism. Densities of overwintering monarchs reported by Calvert (2004) and Brower et al., (2004) may have differed for climatic, seasonal, behavioral, population size, or habitat-related reasons. Our climate regression suggested approximately half of the variation in density was attributable to variation in temperature-related climate variation. Remaining variation is likely to be explained by other factors. For instance, Calvert's studies were conducted in 1979 and 1985-1986, whereas Brower et al.'s data were collected in 2002. Similarly, Calvert collected data from the El Picacho and Sierra Chincua colonies, whereas Brower et al.'s findings came from the Zapatero (also known as Sierra Chincua) and Los Conejos (also known as El Rosario) colonies; these colonies occur

342 across the Corredor Chincua-Campanario-Chivati-Huacal (Garcia-Serrano et al., 2004; fig. 2 in 343 Slayback et al., 2007), possibly contributing to environmental variation in density. Further, the 344 methods used to generate these density estimates differed substantially, ranging from capture- 
345 mark-recapture methods to extrapolations based upon mortality estimates and structural

346 characteristics of Oyamel fir trees.

At this time, we have too little information to posit an advantage of one density

estimation method over another, but it is likely that a combination, nay, a mixture, of reasons

contributed to differences in estimates. As a result, the best we can do is acknowledge the extent

of uncertainty in our estimates. The mixture distribution we derived provides a reasonable

articulation of the uncertainty associated with overwinter density estimates. The magnitude of

uncertainty in the estimated density suggests the mean density is known within no better than a

range of $1 / 3$ to 3 times the expected value. Our estimates of uncertainty, however, may change

with changes in assumptions. If we had assumed the branch-based estimate of Calvert (2004)

was correct within a factor of 3,4 or more, for instance, the uncertainty in this estimate would

have also contributed additional uncertainty in the final estimates. We assumed density might

change both within and among years; stochastic variation around an unvarying mean density

would not alter our conclusions, however. Systematic change in mean density, though, especially

as population size declines, could have serious consequences on our inferences. Longtime

observers of the overwintering colony (K. Oberhauser, personal observation, and L. Brower,

personal communication) have suggested in recent years that monarchs are less densely packed

on trees at the edge of the colony compared to trees in the center. Smaller colonies with a higher

ratio of edge to inner trees could lead to uniformly less dense colonies which, in turn, would

result in a systematic decline in density with population size and thus invalidate our application

of density estimates to the current population; as a result, the observed decline in abundance

367 increased understanding of factors contributing to variation in overwinter density. 
Precision of overwinter density estimates can be improved by measuring natural

369

370

371

372

373

374

375

376

377

378

379

380

381

382

383

384

385

386

387

388

389

390

variability in species response to environmental conditions over time and space, focusing on robust parameter measurement and estimation error, and examining assumptions in models or extrapolations of these models. Capture-mark-recapture methods such as those employed by Calvert (2004), but replicated over years and locations, seem to offer the most promising means of accomplishing this goal of improved overwinter density estimation. Capture-mark-recapture is the most common method for estimating population size in butterflies (e.g., Gall, 1984; Bergman, 2001; Baguette \& Schtickzelle, 2003; Haddad et al., 2008), and its systematic use in the high-elevation Oyamel fir forests of central Mexico would enable robust estimates of daily and total overwintering population sizes, as well as survival and emigration probability (Williams et al., 2002). However, capture-mark-recapture methods come at the considerable cost of disturbing overwintering individuals, a practice that is currently disallowed and arguably not prudent given the small population size and the negative impacts of disturbance. Increased disturbance of overwintering individuals quickens fat depletion, disrupts the thermal advantages of communal roosting, and exposes the butterflies to predation and colder temperatures if they are unable to fly back into trees. The structural extrapolations employed by Calvert (2004) also result in considerable disturbance. Thus, while estimating density during the late-December reporting period for World Wildlife Fund-Mexico may be essential for understanding how many monarchs to attribute to the area over which they occur, accurate measurements using traditional approaches may come at considerable risk to the butterflies. Less invasive possibilities for estimating density, such as colorimetric analysis of the intensity and area of occupied trees (Williams \& Brower 2016), may prove to be a rewarding alternative. 
391

392

393

394

395

396

397

398

399

400

401

402

403

404

405

406

407

408

409

410

411

412
Conclusions

Combining the results of several studies conducted between 1979 to 2002, we conclude an estimate of 21.1 million butterflies $\mathrm{ha}^{-1}$ is the most meaningful value when translating area occupied by overwintering monarchs into estimates of population size. While this represents the best of our knowledge to date, the number of studies estimating densities of overwintering monarchs is small, and large discrepancies exist among various estimates, leading to considerable uncertainty. A better understanding of the spatial and temporal factors influencing monarch densities in their overwintering colonies is needed to accurately understand monarch population size, population viability, and characteristics of the environment required for sustaining the species at desired levels of abundance. However, we acknowledge that this information may be difficult to attain, and that continued careful monitoring of area occupied and non-intrusive estimation of relative density, along with an understanding of the degree to which habitat restoration (and degradation, Brower et al., 2016) is occurring, may provide our best understanding of the critical relationship between milkweed availability and monarch numbers.

\section{Acknowledgments}

We thank L. Brower for data used in our analyses. We thank A. Agrawal, L. Brower, A. Shapiro, and an anonymous referee for comments greatly improving the quality of this contribution. Any use of trade, product, or firm names are for descriptive purposes only and do not imply endorsement by the U.S. Government. The views expressed in this article are the authors' own and do not necessarily represent the views of the U.S. Fish and Wildlife Service. 
414

415

416

417

418

419

420

421

422

423

424

425

426

427

428

429

430

431

432

433

434

435

\section{Literature Cited}

Anderson, J.B., \& Brower, L.P. 1996. Freeze-protection of overwintering monarch butterflies in Mexico: critical role of the forest as a blanket and umbrella. Ecological Entomology, 21, 107-116.

Baguette, M., \& Schtickzelle, N. 2003. Local population dynamics are important to the conservation of metapopulations in highly fragmented landscapes. Journal of Applied Ecology, 40, 404-412.

Bergman, K.O. 2001. Population dynamics and the importance of habitat management for conservation of the butterfly Lopinga achine. Journal of Applied Ecology, 38, 1303-1313.

Brower, L.P. 1977. Monarch migration. Natural History 86, 40-53.

Brower, L.P. 1995. Revision a los mitos de Jurgen Hoth. Ciencias, 39, 50-51.

Brower, L.P., Calvert, W.H., Hendrick, L.E., \& Christian, J. 1977. Biological observations of an overwintering colony of monarch butterflies (Danaus plexippus, Danaidae) in Mexico. Journal of the Lepidopterists' Society, 31, 232-242.

Brower, L.P., Kust, D.R., Rendón Salinas, E., García-Serrano, E., Kust, K.R., Miller, J., Fernandez del Rey, C., \& Pape, K. 2004. Catastrophic winter storm mortality of monarch butterflies in Mexico during January 2002. The Monarch Butterfly: Biology and Conservation (ed. by Oberhauser, K.S., \& Solensky, M.J.), pp. 151-166. Cornell University Press, Ithaca, USA.

Brower, L.P., Slayback, D.A., Jaramillo-López, P., Ramirez, I.M., Oberhauser, K.S., Williams, E.H., \& Fink, L.S. 2016. Illegal logging of 10 hectares of forest in the Sierra Chincua monarch butterfly overwintering area in Mexico. American Entomologist, 62,92-97. 
436 Brower, L.P., Taylor, O.R., Williams, E. H., Slayback, D. A., Zubieta, R. R., \& Ramírez, M. I.

437 2012. Decline of monarch butterflies overwintering in Mexico: is the migratory phenomenon 438 at risk? Insect Conservation and Diversity, 5, 95-100.

439 Brower, L.P., Williams, E.H., Slayback, D.A., Fink, L.S., Ramirez, M.I., Zubieta, R.R., Limon440 Garcia, M.I., Gier, P., Lear, J.A., \& Van Hook, T. 2009. Oyamel fir forest trunks provide 441 thermal advantage for overwintering monarch butterflies in Mexico. Insect Conservation and 442 Diversity, 2, 163-175.

443 Brower, L.P., Williams, E.H., Fink, L.S., Slayback, D.A., Ramirez, M.I., Garcia, M.V.L., 444 Zubieta, R.R., Weiss, S.B., Calvert, W.H., \& Zuchowski, W. 2011. Overwintering clusters of the monarch butterfly coincide with the least hazardous vertical temperatures in the Oyamel forest. Journal of the Lepidopterists' Society, 65, 27-46.

Brower, L.P., Williams, E.H., Fink, L.S., Zubieta, R.R., \& Ramirez, M.I. 2008. Monarch butterfly clusters provide microclimatic advantages during the overwintering season in Mexico. Journal of the Lepidopterists' Society, 62, 177-188.

Calvert, W.H. 2004. Two methods estimating overwintering monarch population size in Mexico. The Monarch Butterfly: Biology and Conservation (ed. by Oberhauser, K.S., \& Solensky, M.J.), pp. 121-127. Cornell University Press, Ithaca, New York, USA.

Calvert, W.H., \& Brower, L.P. 1986. The location of monarch butterfly (Danaus plexippus L.) overwintering colonies in Mexico in relation to topography and climate. Journal of the Lepidopterists' Society, 40, 164-187.

456 Center for Biological Diversity, the Center for Food Safety, the Xerces Society for Invertebrate 457 Conservation, \& Brower, L. 2014. Petition to protect the monarch butterfly (Danaus 458 plexippus plexippus) under the Endangered Species Act. 
$460 \quad$ September 2015.

461

462

463

464

465

466

467

468

469

470

471

472

473

474

475

476

477

478

479

480

481

Dufresne, D. 2004. The log-normal approximation in financial and other computations. Advances in Applied Probability, 36, 747-773.

Gall, L.F. 1984. The effects of capturing and marking on subsequent activity in Boloria acrocnema (Lepidoptera: Nymphalidae), with a comparison of different numerical models that estimate population size. Biological Conservation, 28, 139-154.

Garcia-Serrano, E., Reye, J.L., \& Alvarez, B.X.M. 2004. Locations and area occupied by monarch butterflies overwintering in Mexico from 1993 to 2002. The Monarch Butterfly: Biology and Conservation (ed. by Oberhauser, K.S., \& Solensky, M.J.), pp. 129-133. Cornell University Press, Ithaca, New York, USA.

Haddad, N.M., Hudgens, B., Damiani, C., Gross, K., Kuefler, D., \& Pollock, K. 2008.

Determining optimal population monitoring for rare butterflies. Conservation Biology, 22, 929-940.

Limpert, E., Stahel, W.A., Abbt, M. 2001. Log-normal distributions across the sciences: keys and clues. BioScience, 51, 341-352.

Machtans, C.S., \& Thogmartin, W.E. 2014. Understanding the value of imperfect science from national estimates of bird mortality from window collisions. Condor, 116, 3-7.

McLachlan, G.J., \& Peel, D. 2000. Finite mixture models. Wiley Series in Probability and Statistics, John Wiley and Sons, New York, New York, USA.

Nail, K.R., Stenoien, C., \& Oberhauser, K.S. 2015. Immature monarch survival: effects of site characteristics, density, and time. Annals of the Entomological Society of America, 108, 680-690. 
482 Pearson, R.K. 2011. Exploring data in engineering, the sciences, and medicine. Oxford

$483 \quad$ University Press, Oxford, UK.

484 Pleasants, J. 2015. Monarch butterflies and agriculture. Monarchs in a changing world: Biology

485 and conservation of an iconic butterfly (ed. by Oberhauser, K.S., Nail, K.R., \& Altizer, S.

486 M.). pp. 169-178. Cornell University Press, Ithaca, New York, USA.

487 Pleasants, J. 2017. Milkweed restoration in the Midwest for monarch butterfly recovery:

488 estimates of milkweeds lost, milkweeds remaining and milkweeds that must be added to

489 increase the monarch population. Insect Conservation and Diversity, doi: 10.1111/icad.12198

490 Pleasants, J.M., Oberhauser, K.S. 2013. Milkweed loss in agricultural fields because of herbicide

491

use: Effect on the monarch butterfly population. Insect Conservation and Diversity, 6, 135-

492

144.

493

Pollinator Health Task Force. 2015. National strategy to promote the health of honey bees and other pollinators.

496 https://www.whitehouse.gov/sites/default/files/microsites/ostp/Pollinator\%20Health\%20Strat

497

498

499

500

501

502

503 egy\%202015.pdf 7 August 2015.

Rendón-Salinas, E., \& Tavera-Alonso, G. 2014. Monitoeo de la superficie forestal ocupada por las colonias de hibernación de la mariposa Monarca en diciembre de 2013. World Wildlife Fund-México, Zitácuaro, Michoacán.

http://awsassets.panda.org/downloads/monitoreo mariposa monarca en mexico 20132014 .pdf 7 August 2015.

Schrödinger, E. 1944. What is life? The physical aspect of the living cell. Cambridge University Press, Cambridge, UK. 
504 Semmens, B.X., Semmens, D.J., Thogmartin, W.E., Wiederholt, R., López-Hoffman, L.,

505 Diffendorfer, J.E., Pleasants, J., Oberhauser, K., \& Taylor, O. 2016. Quasi-extinction risk

506 and population targets for the Eastern, migratory population of monarch butterflies (Danaus

507 plexippus). Scientific Reports, 6, 23265, DOI: 10.1038/srep23265.

508 Shapiro, A.F. 2009. Fuzzy random variables. Insurance: Mathematics and Economics, 44, 307509314.

510 Slayback, D.A., Brower, L.P., Ramirez, M.I., \& Fink, L.S. 2007. Establishing the presence and

511 absence of overwintering colonies of the monarch butterfly in Mexico by the use of small

$512 \quad$ aircraft. American Entomologist, 53, 28-39.

513 Sugihara G. 1980. Minimal community structure: An explanation of species abundance patterns.

$514 \quad$ American Naturalist, 116, 770-786.

515 Trudeau, J., B. Obama, and E. P. Nieto. 2016. North American Climate, Clean Energy, and

516 Environment Partnership Action Plan. https://www.whitehouse.gov/the-press-

517 office/2016/06/29/north-american-climate-clean-energy-and-environment-partnership-action

518 Tuskes, P. M., \& Brower, L. P. 1978. Overwintering ecology of the monarch butterfly, Danaus

519 plexippus L., in California. Ecological Entomology 3:141-153.

520 Urquhart, F.A., \& Urquhart, N.R. 1976. The overwintering site of the eastern population of the

521 monarch butterfly (Danaus p. plexippus Danaidae) in southern Mexico. Journal of the 522 Lepidopterists' Society, 30, 153-158.

523 Vidal, O., López-García, J., \& Rendón-Salinas, E. 2014. Trends in deforestation and forest 524 degradation after a decade of monitoring in the Monarch Butterfly Biosphere Reserve in 525 Mexico. Conservation Biology, 28, 177-186. 
526 Vidal, O., \& Rendón -Salinas, E. 2014. Dynamics and trends of overwintering colonies of the

527 Monarch Butterfly in Mexico. Biological Conservation, 180, 165-175.

528 Wilks, D. S. 2006. Statistical methods in the atmospheric sciences, $2^{\text {nd }}$ edition. Academic Press,

529 Burlington, Massachusetts.

530 Williams, B.K., Nichols, J.D., \& Conroy, M.J. 2002. Analysis and management of animal 531 populations. Academic Press, New York.

532 Williams, E.H., \& Brower, L.P. 2015. Microclimate protection of overwintering monarchs 533 provided by Mexico's high-elevation Oyamel fir forests. Monarchs in a changing world: 534 Biology and conservation of an iconic butterfly (ed. by Oberhauser, K.S., Nail, K.R., \& 535 Altizer, S. M.). pp. 109-116. Cornell University Press, Ithaca, USA.

536 Williams, E. H., and L. P. Brower. 2016. A conservation concern: how many monarchs are 537 there? News of the Lepidopterists' Society, 58, 90-93.

538 Zadeh, L.A. 2002. Toward a perception-based theory of probabilistic reasoning with imprecise 539 probabilities. Journal of Statistical Planning and Inference, 105, 233-264. 
540 Figure Legends

541 Figure 1. Presumptive distributions for estimates of overwinter monarch butterfly density in

542 central Mexico. (A) Presumptive distribution for structurally defined density used by Calvert

543 (2004). The vertical gray line is the published estimate. (B) Three capture-mark-recapture

544 methods for estimating density as reported by Calvert (2004), pertinent to the mid-January to

545 early February sampling period. Vertical gray lines are the published estimate. (C)

546 Presumptive distributions for storm-mortality method of density estimation used by Brower

547 et al., (2004) from two colonies, Zapatero (solid line) and Conejos (dashed line); median

548 densities are depicted in gray.

549 Figure 2. A mixture distribution equally combining the individual distributions from the Jolly-

550 Seber, December and January Petersen, Branch, and Brower storm mortality methods (means

551 of the underlying distributions are denoted by the blue lines).

552 Figure 3. (A) Overwinter density of monarch butterflies as a function of mean daily dew point

$553 \quad\left({ }^{\circ} \mathrm{C}\right) .(\mathrm{B})$ Boxplots (median and $1^{\text {st }}$ and $3^{\text {rd }}$ quartiles, with $95 \%$ confidence interval whiskers)

554 of observed daily dew points for each winter month over the period 1977-2015.

555 Figure 4. Annual population size (with 95\% CI), by year winter starts, for monarch butterflies

556 overwintering in Mexico. The black line and associated blue confidence band depict patterns

557 in annual abundance according to the full mixture distribution (i.e., mean density of 20.7

558 million $\left.\mathrm{ha}^{-1}\right)$. The dashed gray line is an upper-end quasi-extinction risk threshold (0.25 ha)

559 described by Semmens et al., (2016). 
560 Table 1. Densities (in millions ha ${ }^{-1}$ ) of monarch butterflies overwintering in central Mexico, by method and source with the estimated 561 standard deviation.

\begin{tabular}{|c|c|c|c|c|}
\hline Method & Publication & Date of Study & Density & SD \\
\hline Petersen capture-mark-recapture & Calvert (2004) & Late-Dec 1985 & 6.9 & 1.2 \\
\hline Jolly-Seber capture-mark-recapture & Calvert (2004) & Early-Jan 1986 & 33.8 & 1.3 \\
\hline Storm mortality-based (Zapatero) & Brower et al., (2004) & Mid-Jan 2002 & 18.4 & 20.1 \\
\hline Storm mortality-based (Conejos) & Brower et al., (2004) & Mid-Jan 2002 & 15.9 & 24.4 \\
\hline Petersen capture-mark-recapture & Calvert (2004) & Late-Jan 1986 & 60.9 & 1.2 \\
\hline Branch extrapolation & Calvert (2004) & ca. Early-Feb 1979 & 10.3 & 2.1 \\
\hline
\end{tabular}


563 Table 2. Density of monarch butterflies overwintering in central Mexico regressed against daily

564 mean temperature, daily mean dew point, and day of year, where $12 \mathrm{Dec}=1,20 \mathrm{Dec}=8,1 \mathrm{Jan}=$

56521 , and $1 \mathrm{Feb}=52 . \mathrm{K}$ is the number of parameters, AICc is the small-sample Akaike's

566 Information Criterion, $\triangle \mathrm{AICc}$ is the difference between the best model and the focal model

$567\left(\mathrm{AICc}_{i}-\min \mathrm{AICc}\right), \mathrm{AICc} \omega$ is the model weight or conditional probability of the model relative

568 to the other models in the model set and LL is the log-likelihood.

\begin{tabular}{lcrrrr}
\hline Variables & K & \multicolumn{1}{l}{ AICc } & \multicolumn{1}{l}{ A AICc } & AICc $\omega$ & \multicolumn{1}{l}{ LL } \\
\hline Dew Point & 3 & 63.90 & 0 & 0.87 & -22.95 \\
Day of Year & 3 & 68.86 & 4.96 & 0.07 & -25.43 \\
Temperature & 3 & 69.40 & 5.50 & 0.06 & -25.70 \\
Temperature + Dew Point & 4 & 92.39 & 28.49 & 0 & -22.20 \\
Dew Point + Day of Year & 4 & 93.44 & 29.54 & 0 & -22.72 \\
Day of Year + Temperature & 4 & 98.57 & 34.67 & 0 & -25.28 \\
\hline
\end{tabular}

569

570

571 
572 Table 3. Observed and fitted area of monarch butterflies overwintering in central Mexico with

573 associated predicted population size (in millions of individuals) and 95\% credible interval.

\begin{tabular}{|c|c|c|c|c|c|}
\hline Start Year & $\begin{array}{c}\text { Observed } \\
\mathrm{Ha}\end{array}$ & $\begin{array}{c}\text { Fitted } \\
\mathrm{Ha}^{*}\end{array}$ & $50 \%$ & $2.50 \%$ & $97.50 \%$ \\
\hline 1993 & 6.23 & 6.79 & 155.4 & 72.5 & 342.6 \\
\hline 1994 & 7.81 & 8.24 & 186.3 & 95.4 & 375.1 \\
\hline 1995 & 12.61 & 12.00 & 267.1 & 133.0 & 529.8 \\
\hline 1996 & 18.19 & 13.80 & 310.3 & 152.4 & 606.1 \\
\hline 1997 & 5.77 & 6.77 & 155.8 & 81.8 & 320.8 \\
\hline 1998 & 5.56 & 6.02 & 136.6 & 71.3 & 267.4 \\
\hline 1999 & 8.97 & 6.95 & 151.2 & 102.7 & 227.1 \\
\hline 2000 & 3.83 & 5.15 & 110.4 & 65.6 & 159.9 \\
\hline 2001 & 9.36 & 7.00 & 151.6 & 103.6 & 235.9 \\
\hline 2002 & 7.54 & 5.11 & 108.8 & 75.5 & 197.4 \\
\hline 2003 & 11.12 & 5.32 & 112.8 & 78.0 & 229.4 \\
\hline 2004 & 2.19 & 2.91 & 65.3 & 45.1 & 98.3 \\
\hline 2005 & 5.91 & 4.15 & 90.3 & 62.6 & 148.2 \\
\hline 2006 & 6.87 & 4.64 & 100.4 & 69.3 & 166.9 \\
\hline 2007 & 4.61 & 4.18 & 90.9 & 62.9 & 140.1 \\
\hline 2008 & 5.06 & 3.37 & 72.4 & 50.3 & 122.1 \\
\hline 2009 & 1.92 & 2.52 & 56.4 & 37.8 & 82.8 \\
\hline 2010 & 4.02 & 3.72 & 82.5 & 55.4 & 119.5 \\
\hline 2011 & 2.89 & 3.18 & 71.6 & 46.3 & 103.5 \\
\hline 2012 & 1.19 & 2.04 & 46.6 & 25.1 & 68.7 \\
\hline 2013 & 0.67 & 1.59 & 37.1 & 16.9 & 54.2 \\
\hline 2014 & 1.13 & 2.17 & 50.9 & 22.8 & 75.7 \\
\hline
\end{tabular}

574 *See Semmens et al., (2016) for details and credible intervals 
575 Figure 1
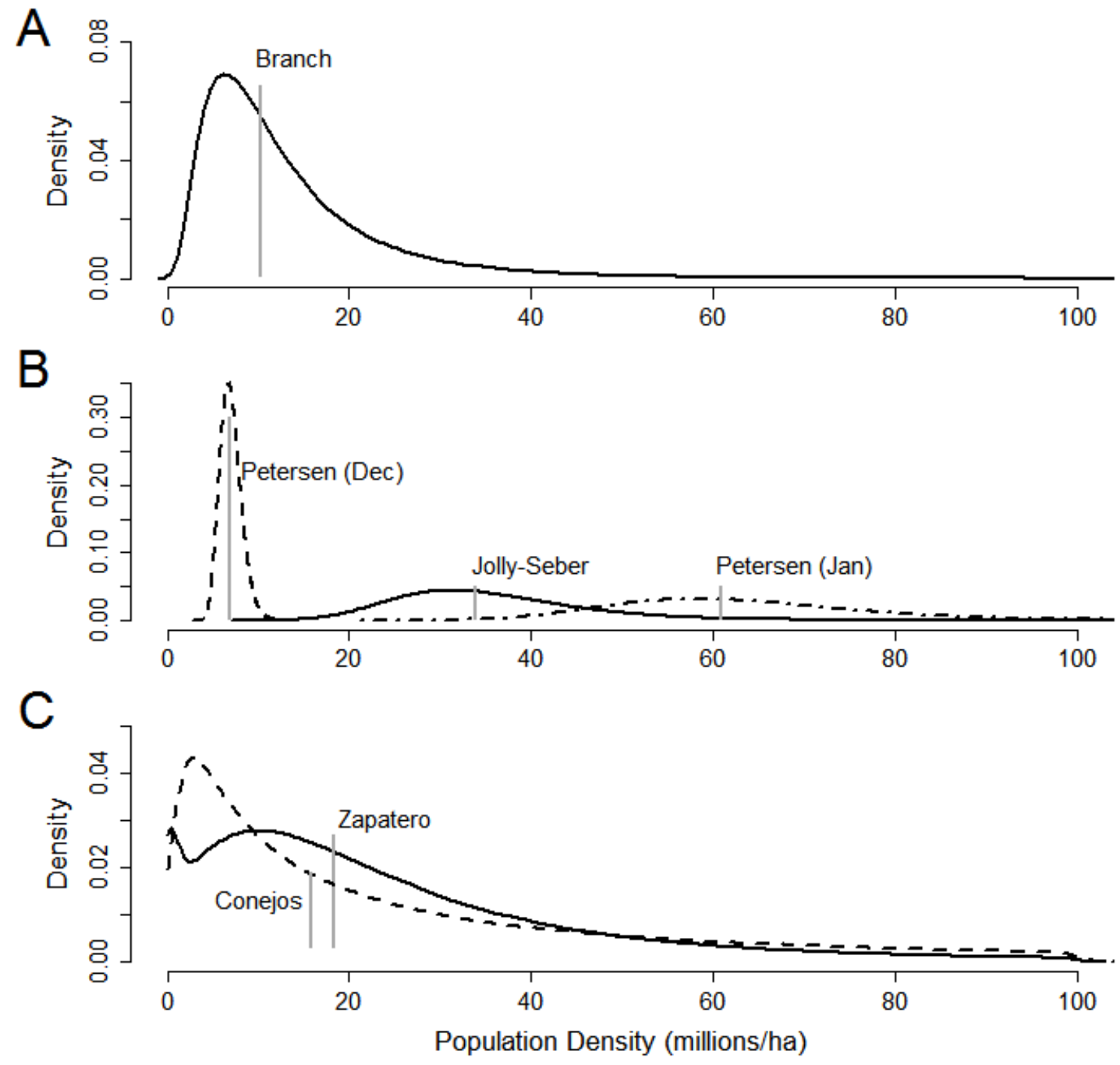

576 
$578 \quad$ Figure 2

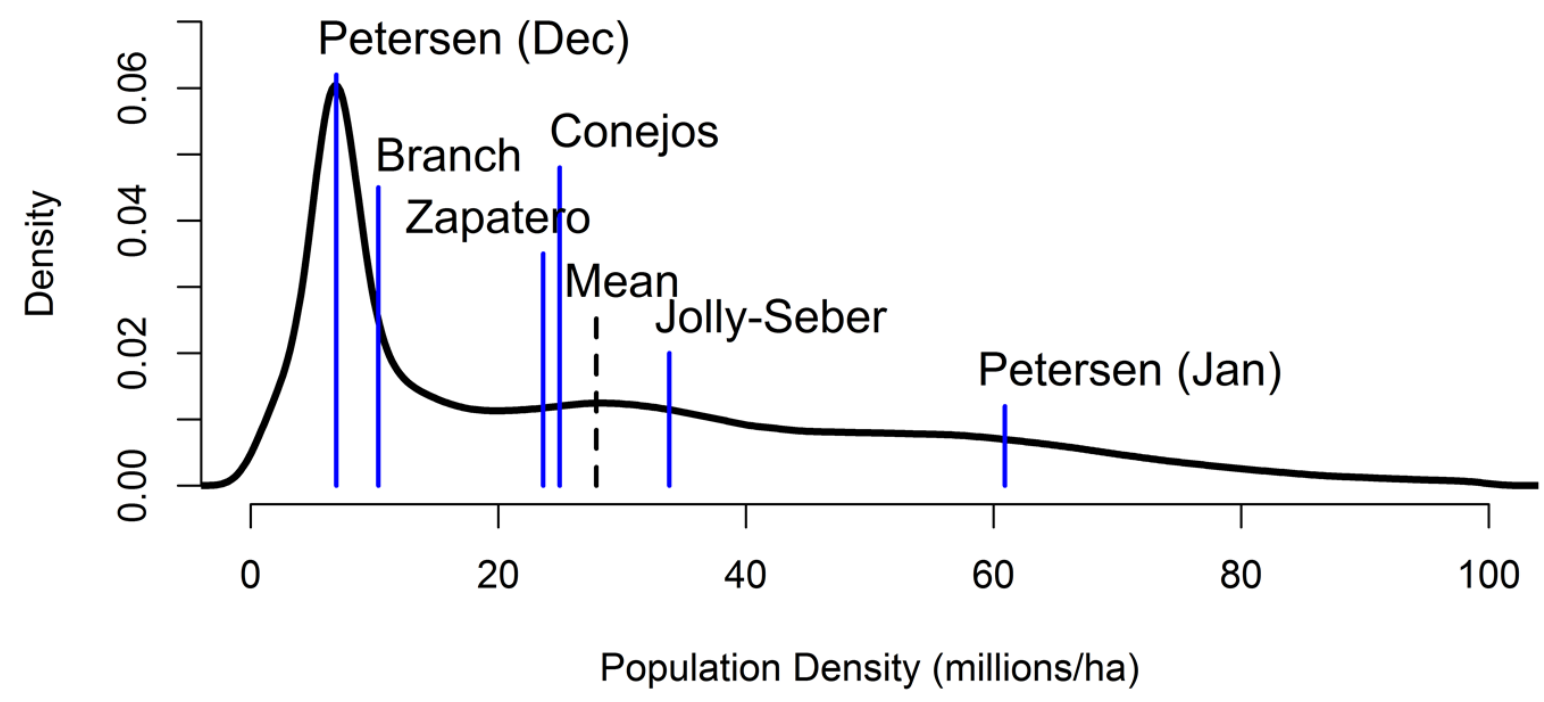

579

580 


\section{Figure 3}

582
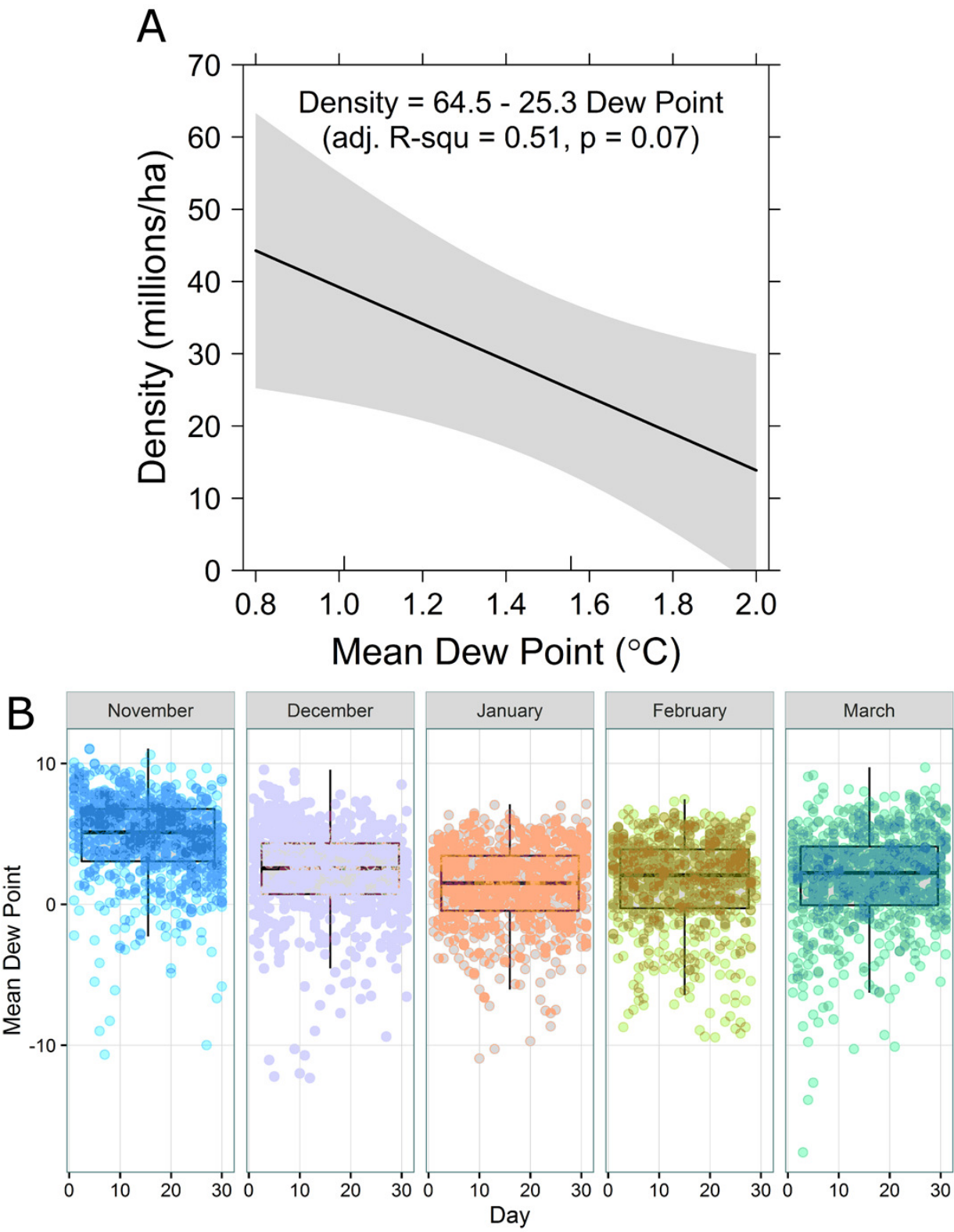

583 
586 Figure 4

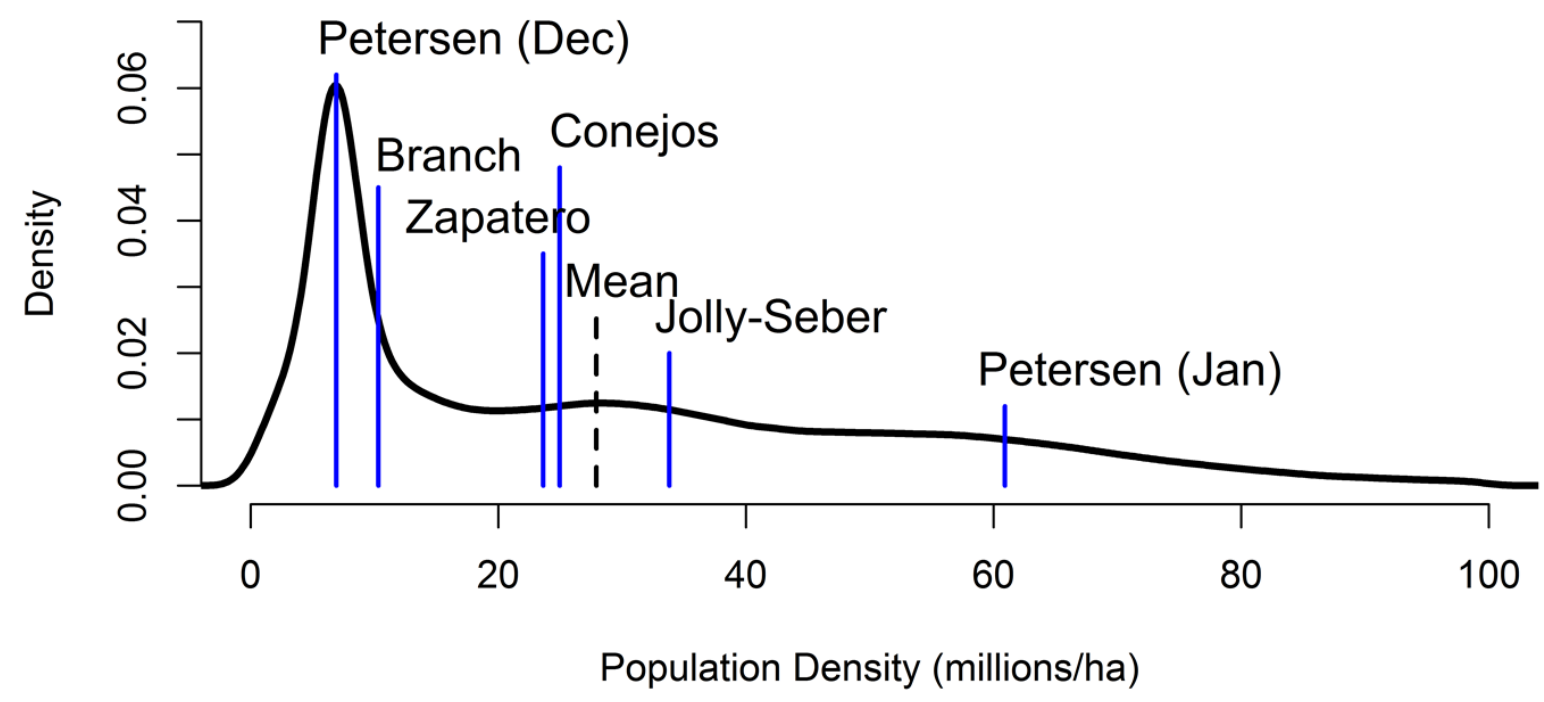

587 